\title{
“Bay Lazarescu'nun Ölümü” Filminin Sağlık Hakkı Bağlamında İncelenmesi
}

\author{
Gamze ÖZBEK GÜVEN ${ }^{* *(D)}$, Şerife YILMAZ ${ }^{2}$ \\ ${ }^{1}$ Asst. Prof. Dr., Malatya Turgut Özal University, Faculty of Medicine, History of Medicine and Ethics \\ Department, Malatya, Turkey \\ ${ }^{2}$ Lecturer Dr., Düzce University, Faculty of Medicine, Faculty of Health Sciences, Nursing Ethics and History \\ Department, Düzce, Turkey
}

Geliş Tarihi/Received: 10.03.2021

Kabul Tarihi/Accepted: 07.07.2021
Doi:10.31200/makuubd.894509

Eleştirel Anlatı/ Critical Narrative

\section{ÖZET}

Dünya genelinde sağlık standartlarının mümkün olan en iyi seviyede tutulması, en önemli sosyal amaçtır. Çünkü sağlık hakkı, en temel insan haklarından biridir. Ulusal ve uluslararası birçok belge ve bildirge ile de teminat altına alınmıştır. Din, dil, ırk, politik görüş, inanç, ekonomik veya sosyal durum ayrımı olmaksızın, tüm insanların bu temel hakka ulaşabilmesi önemlidir. Devletlerin, sağlık hakkı kapsamında, toplumun tüm üyelerinin erişebileceği sağlık hizmetlerini sağlama yükümlülüğünü bulunmaktadır. Sağlık hakkı, devletler tarafından güvence altına alınırken, sağlık çalışanlarına da sorumluluklar yükler. Sağlık personellerinin, sağlık hakkı ve sağlı hizmetlerine erişimde, bu sorumlulukların bilinci ile davranmaları etik açıdan önemlidir. Bu çalışmada, "Bay Lazarescu'nun Ölümü” (The Death of Mr. Lazarescu) filmi sağlık hakkı ve bu hakka erişim bağlamında incelenmiştir. Film, sağlık hakkı kapsamında sağlık hizmetlerinin ulaşılabilirliği ile ilgili düşünsel bir süreç yaşatmaktadır. "Bir insanın sağlık hizmeti alması bu kadar zor olmamalı” dedirten film, sağlık hakkına erişim konusunda yaşanan sorunlara ve sağlık sistemlerine ayna tutmaktadır. $\mathrm{Bu}$ nedenle filmin sağlık personelinin etik eğitimlerinde ders materyali olarak kullanılabileceği önerilmektedir.

Anahtar kelimeler: Sağlık Hakk1, Mr. Lazarescu’nun Ölümü, Eleştirel Anlatı. 


\title{
Review of "The Film Death of Mr. Lazarescu" within The Context of The Right to Health
}

\begin{abstract}
Keeping the best possible level of health standards throughout the world, it is the most important social objectives. Because the right to health is one of the most fundamental human rights. It is also guaranteed by many national and international documents and declarations. It is important that all people have access to this fundamental right, regardless of religion, language, race, political opinion, belief, economic or social status. States have an obligation to provide health services accessible to all members of society, within the scope of the right to health. While the right to health is guaranteed by the states, it also imposes responsibilities on health workers. It is ethically important for health personnel to act with the awareness of these responsibilities in the right to health and access to health services. In this study, the movie "The Death of Mr. Lazarescu" is examined in the context of the right to health and access to this right. The film provides an intellectual process regarding the accessibility of health services within the scope of the right to health. The movie that made people say "It shouldn't be this hard for a person to get health care", mirrors the problems experienced in accessing the right to health and health systems. For this reason, it is suggested that the film can be used as a course material in the ethics education of health personnel.
\end{abstract}

Keywords: Right to Health, The Death Mr. Lazarescu, Critical Narrative.

\section{GÍRİŞ}

Dünya Sağlık Örgütü (DSÖ) tarafından “tam bir iyilik hali” olarak ifade edilen sağlık, bütün insanlar için bir hak olarak tanımlanmıştır. Irk, dil, din, kültür, yaş, cinsiyet, ekonomik ve sosyal durum ayrımı gözetmeksizin, ulaşılabilecek en yüksek sağlık standartlarından yararlanmak bütün insanların en temel hakkıdır (WHO, 2020). Bu hak ulusal ve uluslararası birçok belge ve bildirgede "sağlık hakkı" olarak ifade edilmiştir. Sağlık hakkı; "mevcut sağlık sisteminde kişinin hasta olmadan önceki süreçte sağlığının korunması ve her kişiye nitelikli, eşit tıbbi bakım ve tedaviye ulaşabilme imkânının sağlanması" olarak tanımlanmaktadır (Alptekin, 2004, s.134).

Sağlık hakkı ilk kez DSÖ’nün 1946 tarihli Anayasası'nda düzenlenmiştir. DSÖ Anayasasına göre "sağlık bir bütün olarak fiziksel, ruhsal ve sosyal esenlik durumudur ve yalnızca hastalık ya da maluliyet yokluğu değildir. Ulaşılabilir en yüksek sağlık 
standartlarından yararlanma, 1rk, din, siyasi görüş, ekonomik ya da sosyal durum fark1 gözetilmeksizin her insanın temel haklarından biridir”. Sağlık hakkı 1948 yılında İnsan Hakları Evrensel Beyannamesi'nin kabul edilmesiyle de evrensel bir hak haline gelmiştir (Arslan, 2015, s.45). Beyannamenin 2.maddesinde "Herkes, ,rk, renk, cinsiyet, dil, din, siyasal ya da başka herhangi bir düşünce, ulusal ya da toplumsal köken, servet, doğuş veya başka herhangi bakımdan ayrım gözetilmeksizin bu bildiride ilan olunan tüm haklardan ve özgürlüklerden yararlanabilir."; 25. maddesinde ise "Herkesin, gerek kendisi gerek ailesi için yiyecek, giyim, konut, tıbbi bakım ve gerekli sosyal hizmetler de dâhil olmak üzere, sağlık ve refahını sağlayacak uygun bir yaşam düzeyine ve işsizlik, hastalık, sakatlık, dulluk, yaşl11ık veya geçim olanaklarından kendi iradesi dışında yoksun bırakacak başka durumlarda güvenliğe hakkı vardır." ifadesiyle sağlık hakkına vurgu yapılmaktadır (İnsan Hakları Evrensel Beyannamesi, 1948). 1978'de Alma Ata'da gerçekleştirilen Temel Sağlık Hizmetleri Uluslararası Konferansı'nda da sağlığın temel insan haklarından olduğu, bu hakkın herkes için ulaşılabilecek en iyi seviyede sağlanmasının önemli sosyal amaçlardan biri olduğu ifade edilmiştir (Alma Ata Bildirgesi, 1978). Türkiye Cumhuriyeti (T.C.) Anayasası'nın 56. maddesine göre ise; "Herkes, sağlıklı ve dengeli bir çevrede yaşama hakkına sahiptir." (T.C. Anayasas1, 1982).

Sağlık hakkı insan hakları kapsamında ikincil kuşak haklar arasında yer almaktır (Kaboğlu, 2002). Alman Hukukçu Jellinek'in sınıflandırmasına göre ise pozitif haktır. Böylece kişinin sağlığının korunmasını ve geliştirilmesini, hasta olduğunda tedavisinin sağlanmasını devletten isteme ve alma boyutu önem kazanmaktadır (Temiz, 2014, s.168). Devletlerin ise toplumun tüm üyelerinin erişebileceği sağlık hizmetlerini sağlama yükümlülüğünü bulunmaktadır (Aksoy, 2013, s.839). Bu yükümlülük gereği devletler sağlık politikalarını, sağlık hizmetlerine erişimi engellemeyecek, sağlıkta eşitsizliklere yol açmayacak, bilakis eşitsizlikleri ortadan kaldıracak biçimde düzenlemelidir (Kılıç, 2020).

Bu çalışmada "Bay Lazarescu'nun Ölümü” (The Death of Mr. Lazarescu) filmi sağlık hakkı kavramı açısından değerlendirilmiştir. Film, sağlık hakkı ve ihtiyaç duyulduğu anda sağlık hizmeti alma hakkının ulaşılabilirliği ile ilgili düşünsel bir süreç yaşatmaktadır. Yönetmeni Cristi Puiu'olan “Bay Lazarescu'nun Ölümü” filmi Cannes Film Festivali’nde "Belirli Bir Bakış” ödülü dâhil çeşitli festivallerde toplam 25 ödüle layık görülmüş̧ür ve Romen Sineması'nın en büyük başyapıtlarından biri olarak kabul edilmektedir. 


\section{BULGULAR VE TARTIŞMA}

Filmin kahramanı Bay Lazarescu yaşlı, hasta, bakımsız ve yalnız yaşayan biridir. Yıllar önce ülser nedeniyle ameliyat olan Lazarescu'nun ağrısı vardır ve kendisini kötü hissetmektedir. Birkaç kez aramasına rağmen ambulansa ulaşamaz. Komşularından yardım ister. Komşuları da ona yardım edemeyeceklerini anladıklarında ambulans çağırırlar. Gelen görevli alkol kullanan, evde kedileriyle yalnız yaşayan, bakımsız görünen Bay Lazarescu’yu hastaneye götürmeye karar verir.

Bay Lazarescu'nun ambulansa bindirilmesi ile sağlık sistemi içindeki zorlu yolcuğu başlar. Bir hastaneden diğerine sürüklenir, yanlış teşhis koyulur. Doğru teşhis koyulana kadar epeyce zaman kaybedilir ve gittikçe durumu kötüleşir. Bay Lazarescu'nun bilinci bozulur ve konuşması güçleşir. Yanındaki sağlık görevlilerinin çabaları ile bir hastanede tetkikler yapılır ve beyin kanaması geçirdiği, acilen ameliyata alınması gerektiği tespit edilir. Ancak Bay Lazarescu'yu ameliyat edecek hastane bulunması gerekir. Gittikleri bir hastanede hekimler hastadan onam alamadıkları için hastayı ameliyat etmek istemezler.

Bay Lazarescu'yu evinden alan ve sağlık hizmeti alamamasının en büyük sıkıntısını yaşayan ambulans görevlisi hemşire, hastanın iyiliği açısından acil ameliyata alınması gerektiğini söyleyerek hekimlerle tartışır. Ancak çok sert bir tepki alır. Hastanın tedavi olma hakkı kadar, hekimlerin de yasalar karşısında ondan ya da yakınlarından onam almak zorunda olduğu söylenir. Ancak bunu söyleyen hekimler hastanın aciliyetini ve bilinç durumunu çok önemsemezler. Hastanın ameliyatı reddettiği gerekçesiyle hastayı geri gönderirler. Sonunda ambulans görevlisi hastayı başka bir hastaneye götürmek zorunda kalır. Oradaki hekim hastayı kabul eder ve ameliyat için hasta hazırlık odasına alınır.

Bir insanın sağlık hizmeti alması bu kadar zor olmamalı dedirten film, sağlık hakkı bağlamında sunulan sağlık hizmetlerini değerlendirmemize firsat vermektedir. Sağlık hakkı; insanı yaşamın en değerli varoluşu kabul ederek onun bütün yönleriyle kişiliğini korumayı ve geliştirmeyi amaçlayan insan haklarından biridir (Arslan, 2015, s.39). Bu hak ihtiyaç duyulduğu anda sağlık hizmeti alma hakkını beraberinde getirir. Sağlık hizmeti; “insan sağlığına zarar veren çeşitli etmenlerin yok edilmesi ve toplumun bu etmenlerin etkilerinden korunması, hastaların tedavi edilmesi, bedensel ve ruhsal yetenek ve becerileri azalmış olanların rehabilite edilmesi için yapılan hizmetlerdir." (Sağlık Hizmetlerinin Yürütülmesi Hakkında Yönerge, 2005). İnsanların bu hizmetleri alırken yararlandığı haklar da "hasta hakları" olarak tanımlanmaktadır. Bu haklar; hasta insanların sağlıklarına yeniden kavuşmak için yardım aldığı 
sağlık hizmeti uygulayıcılarıyla aralarındaki ilişkilerde söz konusu olan hakların bütünüdür. Bu haklar başta; İnsan Hakları Evrensel Beyannamesi ve Anayasa olmak üzere birçok uluslararası ve ulusal sözleşme ve bildirgelerle teminat altına alınmıştır.

Her insanın adalet ve eşitlik ilkeleri çerçevesinde sağlık hizmetlerinden faydalanma, 1rk, dil, din ve kültür, yaş, cinsiyet, ekonomik ve sosyal durumları gözetilmeksizin sağlık hizmeti alma hakkı vardır (Hasta Hakları Yönetmeliği, 1998). Bu hasta haklarının en temel özelliğidir. Ayrıca bu hakka istinaden "hastanın bilgi isteme, sağlık kuruluşunu seçme ve değiştirme, personeli tanıma, seçme ve değiştirme, öncelik sırasının belirlenmesini isteme, tıbbi gereklere uygun teşhis, tedavi ve bakım alma, tıbbi özen gösterilmesini isteme hakkı” gibi haklar da belirlenmiştir (Oğuz, 1997). Sağlık hizmetleri planlanıp yürütülmesinde bu haklar göz önünde bulundurulmalıdır.

Sağlık hizmetlerine erişim ve erişimde hakkaniyet, sağlıkta kalite göstergelerinden biridir (Smith vd., 2009; Levesque vd., 2013). Ekonomik Kalkınma ve İş birliği Örgütü (OECD) tarafindan ihtiyaç duyduğu halde sosyal, kültürel ya da ekonomik nedenlerden dolayı sağlık hizmetlerine erişimde sorun yaşayan çok sayıda insan olduğu tahmin edilmektedir (OECD, 2011). Bu nedenle; ülkelerin sağlık hizmetlerine erişim ile ilgili verilerini değerlendirmeleri ve tespit edilen sorunlara çözüm önerileri geliştirmeleri gereklidir.

Sağlık hizmetlerine erişim sağlık hakkı bağlamında devletlerin yükümlülüğü olmasına rağmen bazı durumlarda erişim konusunda sorunlar yaşanabilmektedir. Bu sorunların en temel nedenlerinin başında ekonomik yetersizliklerin geldiği belirlenmiştir. Ayrıca bekleme süresi, uzaklık gibi hizmet sağlayıcıları ile ilgili ve sağlık kurumlarına ilişkin birtakım faktörlerin etkili olduğunu tespit edilmiştir (Chaupain-Guillot \& Guilot, 2015). Sağlık kurumlarına ilişkin faktörlerin başında ise kaynakların sınırlı olması sorunu gelmektedir. Sağlıkta imkânlar, malzemeler, en önemlisi de insan gücü sınırlıdır. Sağlık sunumunda gereksinim olan bu kaynakların sınırlılığı nedeniyle sağlık hakkının ulaşılabilirliğinde sıkıntılar yaşanmaktadır (Ekmekçi \& Arda, 2015, s.6). Eldeki imkânların nasıl dağıtılacağı ve kullanılacağı konusunda tartışmalar yıllardır süregelmektedir. Hizmeti alan, hizmeti sunan ve hizmetin sağlayıcısı açısından yaşanılan sıkıntılar sağlık hakkında etik ihlaller yaşanmasına neden olabilmektedir. Filmde de sağlı hizmetine erişimde yaşanan sorunların çarpıcı biçimde ekrana yansıdığı görülmektedir. Bay Lazarescu, gece yaşanan kazaya bağlı yoğunluk yaşandığı gerekçesiyle hastanelere kabul edilmemiştir. Acil tomografi çekilmesi gerekirken boş cihaz olmaması, ameliyat olması gerekirken ameliyathanenin dolu olması ve hastanede boş yatak olmaması gibi 


\section{Özbek Güven, G. \& Yılmaz, Ş.}

gerekçelerle hastane hastane dolaşmak zorunda kalmıştır. Hekimin "Onu burada tutardım, ama yerimiz yok" şeklindeki ifadesi sınırlı kaynak nedeniyle sağlık hizmetine erişim sorununun ekrana yansıyan bir örneğidir.

Bay Lazerascu, yer olmadığ gerekçesiyle kendisini hastaneye yatıramayan hekime "Hekimlerin görevi hastalara yardım etmek değil mi?” diye sorar. Bu soru tıp etiği temel ilkeleri olan zarar vermeme, yarar sağlama, özerklik ve adalet ilkelerine vurgu yapar. Bu ilkeler karşısında hastanedeki yoğunluk kabul edilebilir bir gerekçe olamaz. Etik olarak sağlık çalışanlarının öncelikle hastaya zarar vermeyerek, hastanın yararını ve özerkliğini gözeterek herkese adil ve eşit sayılabilecek nitelikte sağlık hizmeti sunması gerekir. Çünkü sağlık hakkı bağlamında hasta haklarını düzenleyen tüm yasal metinler hastanın yararını, zarar görmemesini, özerkliğini ve hakça bir sağlık hizmeti alabilmesini hedefler (Oğuz, 2000, s.112). $\mathrm{Bu}$ hedef doğrultusunda sağlık personeli ile hasta arasındaki ilişkiyi düzenler.

Filmde hastanın özerkliğinin tıp uygulamalarına yansıması olan bilgilendirilmiş onamla ilgili yaşanılan sıkıntılara da dikkat çekilmektedir. Tıbbi bir uygulama gerçekleştirirken hem yasal hem de etik açıdan kişilerin rızasının alınması önemli bir husustur. Bu rızanın şartları mevzuatla belirlenmiştir. Filmde hastayı ameliyata almayan hekimler hasta veya yakınından onam alamamayı gerekçe olarak sunmuşlardır. Bu arada hastanın bilinç durumu ve aciliyeti göz ardı edilmiştir. Filmin sonunda hasta başka bir hastanede ameliyata hazırlanırken görülmektedir. Hastaneler arasındaki uygulama farklılıkları bilgilendirilmiş onam ile ilgili yaşanılan sıkıntıları gözler önüne sermektedir.

Sağlık hizmetlerinden yararlanabilmek için hastane hastane dolaşan hastanın durumu gittikçe kötüleşirken onu yalnız bırakmayıp sahip çıkan tek kişi ambulans görevlisi hemşiredir. Hastanın durumunun giderek ciddileşmesine tanık olan ve mutlaka tedavi olması gerektiğinin farkında olan hemşire, savunucu rolünü sonuna kadar kullanmıştır. Hastasının iyiliği ve yararı için gerektiğinde sağlık çalışanları ile tartışmaya girmiş ve haklarını korumaya çalışmıştır. Sağlık personelinin kişinin sağlık hakkına erişimini sağlamada önemli bir pozisyonda olduğunu göstermiştir.

\section{SONUÇ}

Sağlık hakkı, sağlık hizmetlerinin planlanmasından yürütülmesine kadar her aşamada korunması gereken bir kavramdır. Bu kavram varoluşun en değerli varlığı kabul edilen insanın yaşamını korumak ve sürdürmekle temellendirilir. Herkese adil ve eşit olarak verilmesi gereken 
sağlık hakkı devlet tarafından güvence altına alınırken sağlık çalışanlarına da sorumluluklar yükler. Sağlık personellerinin sağlık hakkı ve sağlık hizmetlerine erişimde bu sorumlulukların bilinci ile davranmaları etik açıdan önemlidir. "Bay Lazarescu'nun Ölümü” filmi sağlık hakkına erişim konusunda yaşanan sorunlara ve sağlık sistemlerine ayna tutmaktadır. Bu nedenle filmin sağlık personelinin etik eğitimlerinde ders materyali olarak kullanılabileceği önerilmektedir.

\section{REFERENCES / KAYNAKLAR}

Aksoy, B. (2013). 14. Çalışma ekonomisi ve endüstri ilişkileri kongresi bildiriler kitabı. Sağlık hakkı bağlamında sivil toplum örgütlerinin eylemlerinin sosyal politikalara katkılarl (ss. 837-864). İstanbul: Türk-İş Yayınları.

Alptekin, K. (2004). Sağlık hakkı ve insan hakları üzerine bir değerlendirme. T Klin Tıp Etiği-Hukuku-Tarihi, 12, 132-139.

Arslan, K. O. (2015). Bir temel hak olarak sağlık hakkı. Ë̈HFD, 9, 1-2.

Bay Lazarescu'nun Ölümü. (2005). Erişim tarihi: 23.11.2020, https://filmhafizasi.com/the-death-of-mr-lazarescu$\underline{2005 .}$

Chaupain-Guillot, S., \& Guillot, O. (2015). Health system characteristics and unmet care needs in Europe: An analysis based on EU-SILC data. The European Journal of Health Economics, 16(7), 781-796.

Ekmekçi, P. E., \& Arda, B. (2015). Temel etik kuramlar açısından adalet ve sağlık hakkı kavramlarının değerlendirmesi. Türkiye Klinikleri J Med Ethics, 23(1), 6-21. doi: 10.5336/mdethic.2014-42622.

$\begin{array}{lllll}\text { Hasta Hakları } & \text { Yönetmeliği. } & \text { (1998). } & \text { Erişim } & \text { tarihi: }\end{array}$ https://www.mevzuat.gov.tr/mevzuat?MevzuatNo=4847\&MevzuatTur=7\&MevzuatTertip=5

İnsan Hakları Evrensel Beyannamesi. (1948). Erişim tarihi: 23.11.2020, https://apps.who.int/gb/bd/pdf files/BD 49th-en.pdf\#page=7

Kaboğlu, İ. (2002). Özgürlükler hukuku (7. bask1). Ankara: İmge Kitabevi.

Kılıç, M. (2020). Socio-legal dynamics of the right to health in the face of pandemic threat. Yıldırım Beyazıt Law Rewiev, (2), 1-46.

Levesque, J. F., Harris, M. F., \& Russell, G. (2013). Patient-centred access to health care: Conceptualising access at the interface of health systems and populations. International Journal for Equity in Health, 12(1), 18.

Oğuz, N. Y. (1997). Hasta hakları alanındaki gelişmeler ve değişen değerler. Türkiye Klinikleri Tıbbi Etik Dergisi, $5(2), 50-55$.

Oğuz, N. Y. (2000). Hastayım, o halde hakkım. Şizofreni Yazıları Dergisi, 1(3), 12-16.

Organisation for Economic Co-operation and Development-OECD. (2011). Health at a glance 2011. Erişim tarihi: 30.06.2021, https://www.oecd.org/els/health-systems/49105858.pdf

Sağlık Hizmetlerinin Yürütülmesi Hakkında Yönerge. (2005). Erişim tarihi: 23.11.2020, https://www.ttb.org.tr/mevzuat/index.php?option=com_content\&id=2402

Smith, P. C., Mossialos, E., Leatherman, S., \& Papanicolas, I. (2009). Performance measurement for health system improvement: Experiences, challenges and prospects. Cambridge: Cambridge University Press. 
Temel Sağlık Hizmetleri Uluslararası Konferansı Alma Ata Bildirgesi. (1978). Erişim tarihi: 23.11.2020, https://www.ttb.org.tr/mevzuat/index.php?option=com_content\&view=article\&id=521:temel-saik$\underline{\text { hmetleruluslararasi-konferansi-bdalma-ata\&catid=6:uluslararasylge } \& \text { Itemid }=36}$

Temiz, Ö. (2014). Türk hukukunda bir temel hak olarak sağlık hakk1. Ankara Üniversitesi SBF Dergisi, 69(1), 165-188.

Türkiye Cumhuriyeti Anayasası.

https://www.tbmm.gov.tr/anayasa/anayasa_2018.pdf

(1982). Erişim tarihi:

23.11.2020,

World Health Organization. (2020). Basic documents: Forty-ninth edition. Erişim tarihi: 23.11.2020, https://apps.who.int/gb/bd/pdf files/BD 49th-en.pdf\#page $=7$ 